\title{
Centellas sagradas. El culto al rayo en los Andes centrales
}

\author{
Sacred thunder. \\ The cult to lightning in central Andes
}

Silvia Limón Olvera*

Resumen: A través de diversos documentos de los siglos XVI y XVII, en este artículo se analiza el culto que rindieron al dios del rayo los llacuaces, antiguos pobladores de la sierra central y norcentral de Perú. El objetivo del trabajo es mostrar cómo las creencias y prácticas rituales de los habitantes de esa región sirvieron como eje rector e incidieron en la jerarquía social de esas comunidades. La investigación arrojó como resultado que los ancestros fueron equiparados con el dios patrono, mientras que sus descendientes justificaron su posición privilegiada dentro de la sociedad a través de ese parentesco.

Palabras Clave: Andes, Indígenas, Creencias, Ritos, Rayo.

ABSTRACT: Based on documents from the XVI and XVII centuries, this article analyzes the way the Llacuaces, ancient settlers of the central and north central mountains of Peru, worshiped the god of lightning. The aim is to show the way beliefs and ritual practices of the inhabitants of that region served as a pattern and influenced the social hierarchy of these communities. The result of the research was that ancestors were compared to the patron god and their descendants justified their privileged position in society as a result of that relationship.

KEY WORDS: Andes, Natives, Beliefs, Rituals, Lightning. 


\section{INTRODUCCIÓN}

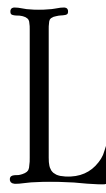

as crónicas cusqueñas que recogen la historia y las concepciones religiosas de los incas ubican a Illapa, dios del rayo y del trueno ${ }^{1}$ por debajo del Sol o Inti, numen tutelar del grupo hegemónico, e incluso lo definen como su sirviente. ${ }^{2}$ Sin embargo, diversos documentos provenientes de la sierra central y norcentral de Perú se refieren a él como el dios más destacado. Esto se puede apreciar, por ejemplo, en la obra Dioses y hombres de Huarochirí, en la Relación de los agustinos de Huamachuco y en diversos informes jesuitas, como los provenientes de Anchash, de Huaylas y de la Provincia de Cajatambo, entre otros. En dichos textos se menciona al rayo como divinidad principal y ancestro de los lla-

1 Aunque el fenómeno natural que fue deificado por los pobladores andinos abarca el relámpago y el trueno, me referiré a él como rayo, o con los nombres particulares que le asignaron las diferentes comunidades a las que se hará referencia en este trabajo.

2 Gonzalo Lamana Ferrario [ed.], Pensamiento colonial crítico. Textos y actos de Polo Ondegardo, edición de estudio biográfico de Teodoro Hampe Martínez, Cusco, Centro de Estudios Regionales Andinos "Bartolomé de las Casas"/Instituto Francés de Estudios Andinos, 2012, p. 344. Polo Ondegardo (ca. 1520-1575). Jurista y funcionario de la burocracia española. Se desempeñó como visitador y corregidor en las Provincias de Charcas y Cusco, además de haber sido encomendero. En la década de 1560 escribió diversos informes sobre las poblaciones andinas, de las que proporciona importantes datos sobre la sociedad, la economía, la políica y la religión. Garcilaso de la Vega, Comentarios reales de los incas, ed., índice analítico y glosario de Carlos Araníbar, 2 vols., México, FCE, 1995, vol. I, p. 68. Nació en 1539 en Cusco. Hijo natural de un capitán español y de Isabel Chimpu Ocllo, descendiente directa de Huayna Capac, por lo que perteneció a la más rancia nobleza inca. Por su condición de mestizo conjuntó dos mundos: el indígena y el español. Creció en el ámbito andino de su madre pero también, por disposición de su padre, fue instruido en la cultura occidental, y residió en España desde los 21 años hasta su muerte en 1616. En su obra Comentarios reales, escrita con una prosa excepcional y publicada en 1609, expone de manera cronológica la historia de los incas, sus conquistas y los acontecimientos más relevantes, así como las antiguas costumbres y creencias. Las fuentes que alimentaron su obra fueron múltiples. Tuvo acceso a la tradición oral que le transmitieron sus parientes maternos. Conoció y aprovechó de manera crítica diversos escritos impresos en su época sobre los Andes. Ya en España tuvo correspondencia con sus condiscípulos de escuela en los Andes, quienes le proporcionaron información. A diferencia de otros cronistas, se manifestó en contra de la ilegitimidad y del carácter tiránico de los incas, condiciones que sólo aceptó para Atahualpa. 
cuaces, grupo que habitaba en ayllus que estaban dispersos en las zonas de Huarochirí, Jauja, Atavillos, Ancash, Cajatambo, Recuay y Cajamarca. ${ }^{3}$ Estas dos percepciones, que aparecen en fuentes documentales de procedencia diferente, me lleva a plantear que en las crónicas cusqueñas el rayo fue calificado como una deidad de menor relevancia que el sol porque, como era considerado el ancestro de algunos grupos que fueron avasallados por los incas, su dios pasó a ser el servidor del numen patrono del pueblo dominante. A pesar de esto, el rayo como divinidad siguió ocupando un lugar destacado entre los incas, debido a que se le atribuía el control de los fenómenos meteorológicos que incidían directamente en la agricultura. De esta manera, la hegemonía incaica fue expresada a través de sus propias creencias religiosas, según las cuales la deidad principal de los sometidos ocupaba el tercer lugar de la tríada deífica por debajo de Wiracocha e Inti.

En este artículo me propongo exponer la relevancia que el numen del rayo tuvo entre los pobladores de la sierra central y norcentral de Perú, así como las formas en que las creencias y el culto en torno a él fueron el eje rector de dichas comunidades. Para la elaboración del presente artículo ha sido de gran valor la información contenida en los documentos de los siglos XVI y XVII. Entre ellos destacan los correspondientes a la campaña de extirpación de idolatrías publicados por Pierre Duviols, así como las Cartas Annuas elaboradas por miembros de la Compañía de Jesús y editadas por Mario Polia Meconi.

\section{LOS LLACUACES Y LOS LLACTAS: DOS ETNIAS OPUESTAS}

La sierra central y norcentral de Perú estuvo habitada por llacuaces y llactas, quienes, aunque eran de etnias diferentes, compartían territorios. Así, por ejemplo, en 1621, Rodrigo Hernández Príncipe dice sobre Ocros lo siguiente: "Este pueblo como los demás, están entreverados de pachacas,

3 María Rostworowski, Estructuras andinas del poder. Ideología religiosa y política, Lima, Instituto de Estudios Peruanos, 2007, p. 52. 
y éstas en ayllus de llactas y llacuaces." ${ }^{\prime 4}$ De acuerdo con Pierre Duviols, los llactas, también llamados waris, llegaron a la zona provenientes del occidente, mientras que los llacuaces arribaron más tardíamente desde el oriente. María Rostworoswki establece que unos grupos waris o llactas decían provenir de antiguas poblaciones yungas que emigraron tempranamente del litoral a la sierra, mientras que otros afirmaban que sus progenitores habían salido de una cueva del nevado de Yerupajá, en tanto que los llacuaces llegaron tiempo después desde Yarocaca y Titicaca. ${ }^{5}$

De acuerdo con la información recopilada durante el siglo XVII en Pariac, Pimachi, Hacas y Ocros, los waris y los llacuaces vinieron del Titicaca, aunque algunos ayllus de estos últimos decían que sus ancestros vinieron de Yaro (Yarocaca), como los chaupis y los ayllus Híchoc y Caquimarca, así como las pachacas allauca y chauca churi. Los relatos también señalan otra diferencia, pues mencionan que las pakarinas o lugares de origen de los llacuaces estaban en las punas (tierra alta de la región andina), mientras que las de los waris en los pueblos. Esto corresponde al señalamiento de Duviols de que los primeros se dedicaban al pastoreo de llamas, mientras que los segundos a la agricultura, y establece que se trataba de dos etnias diferentes en oposición y complementariedad. ${ }^{6}$ Las divergencias entre los dos grupos mencionados se notan además porque, de acuerdo con lo consignado en varios documentos del siglo XVII, como el recogido en Santo Domingo de Pariac, los llacuaces decían descender del rayo al que veneraban como deidad principal, mientras que los llactas o waris afirmaban ser hijos del sol.

Asimismo, cabe señalar que algunos relatos presentan a los ancestros de los llactas y llacuaces con características sobrehumanas, lo cual los

4 "Visita de Rodrigo Hernández Príncipe a Ocros (1622)", en Pierre Duviols, Procesos y visitas de idolatría. Cajatambo, siglo XVII, revisión paleográfica de Laura Gutiérrez Arbulú y Luis Andrade Ciudad, selec. de textos y estudios históricos de Pierre Duviols, trad. de textos quechuas de César Itier, Lima, Instituto Francés de Estudios Andinos/ Pontificia Universidad Católica del Perú, 2003, pp. 733 y 734.

5 Rostworoswki, op. cit., p. 52. Pierre Duviols, "Huari y Llacuaz. Agricultores y pastores. Un dualismo prehispánico de oposición y complementariedad", en Revista del Museo Nacional, t. XXXIX, Lima, 1973, pp. 153-191.

6 Loc. cit. 
ubica en el tiempo mítico. Por ejemplo, se refería que los progenitores de los waris eran descendientes de los antiguos gigantes barbados que había creado el sol, salían únicamente de noche, y con sólo mirar hacían sementeras y abrían acequias. También se decía que algunos tenían dos caras, una atrás y otra adelante, y que comían gente. Tenían la capacidad de convertirse en aves y su canto indicaba que vendrían a devorar humanos o presagiaban la muerte de alguien. De los primeros llacuaces se mencionaba que habían sido creados por el rayo y eran invisibles, aunque a veces se dejaban ver, y andaban por debajo de la tierra. ${ }^{7}$

\section{LOS LLACUACES Y EL DIOS DEL RAYO}

De acuerdo con diferentes documentos, los llacuaces tenían como dios patrono al rayo. Por ejemplo, el mito recopilado por Bernardo de Noboa en 1656 en San Francisco de Otuco, doctrina de San Pedro de Hacas, refiere que Apu Libiac Cancharco cayó del cielo en forma de rayo y tuvo muchos hijos que fueron los progenitores de los ayllus chaupis, xulca y allauca. Luego, envió a sus hijos por diversas partes para que conquistaran a los pobladores y se hicieran de tierras donde asentarse. El relato menciona que los llacuaces vencieron a los del ayllu Guari Guachico al enviarles una gran tempestad, lo cual denota su parentesco con la divinidad que controlaba los temporales. ${ }^{8}$

Como se puede apreciar, existió cierta rivalidad entre los llactas y los llacuaces, quienes para reestablecer buenas relaciones, cada uno de estos grupos ofreció al rayo a uno de sus hijos, infantes que, según consignó Rodrigo Hernández Príncipe, eran hermosos, sin manchas ni marcas. Estos niños, luego de haber sido sacrificados, se transformaron en oráculos, al igual que los individuos que habían sido señalados por el dios. De esta manera, se observa que las dos etnias veneraban conjuntamente al rayo

\footnotetext{
"Visitas y procesos de Bernardo de Noboa", en Duviols, Procesos..., pp. 274 y 305. Rostworowski, op. cit., p. 52.

8 "Visitas y procesos de Bernardo de Noboa", en Duviols, Procesos..., p. 226.
} 
o Libiac y una de sus principales fiestas tenía lugar en el contexto de la celebración de Corpus Christi. ${ }^{9}$

En cuanto a la forma en que se articuló la tradición de los llacuaces con la religión impuesta por los incas, existe un caso representativo que lo ejemplifica de manera clara. Me refiero al sacrificio de Tanta Carhua, joven de la población de Ocros que fue ofrecida al sol por su padre Caque Poma. Este personaje es mencionado como uno de los hijos de Caha Yánac, quien era el segundo hijo de la guaca Carhua Huanca, dios del rayo y primer ancestro de los llacuaces de ese lugar. El ofrecimiento de Tanta Carhua le valió a su padre, Caque Poma, ser reconocido por el Inca como cabeza del linaje gobernante del lugar. Es pertinente señalar que, aunque la doncella fue ofrecida al sol o Inti, llevaba el nombre Carhua que, según la fuente, fue impuesto por el Sapa Inca. Sin embargo, dicho apelativo correspondía al del primer ancestro sagrado o guaca de Ocros, lo que la identificaba con el rayo, de quien ella descendía. Además, hay que recordar que este dios quedó supeditado a la deidad solar patrona de los incas.

\section{EL DIOS DEL RAYO Y SU COMPLEJIDAD}

El rayo fue considerado como una entidad divina a la que rindieron culto diferentes pueblos que habitaron en la cordillera andina de Perú, zona donde es común que ese fenómeno meteorológico se manifieste durante la época de lluvias. Dicha deidad aparece mencionada en los documentos de los siglos XVI y XVII con nombres variados, según la región y el grupo de que se trate, lo cual muestra su importancia y sus formas particulares en tanto numen patrono y ancestro de diversas comunidades andinas. Así, por ejemplo, los incas le llamaban Illapa, "rayo o relámpago", término relacionado con emisión de luz y fulguración. De acuerdo con Mario Polia, "La raíz illa-, [...] entra en la composición de vocablos que significan 'centellear', 'relampaguear' y 'rayo'.” En tanto que Diego González Olguín, tra-

9 "Visita de Rodrigo Hernández Príncipe a Recuay (1622)", en ibid., p. 756. Rostworowski, op. cit., pp. 52 y 54. 
duce "Yllappa" como "Rayo, arcabuz, artillería". ${ }^{10}$ En Huamachuco el rayo es mencionado con el apelativo de Catequil, divinidad oracular asociada a la creación y a la fertilidad. En la zona de Huarochirí el fenómeno de las tormentas estuvo personificado en el dios Pariacaca y sus hermanos, mientras que en la región de Huaylas es mencionado como Libiac, apelativo que proviene de llypllaq: "relampagueante". ${ }^{11}$ La deidad también presentó otros nombres dependiendo del grupo o del pueblo donde se le rendía culto, como se verá más adelante. Asimismo, en diversas fuentes, el numen del rayo aparece en forma de triada. De esta manera, Polo Ondegardo menciona que lo llamaban por tres nombres: Chuqui illa, Catu illa, Intiillapa. Felipe Guamán Poma de Ayala refiere que había tres Illapas, el padre y dos hijos. En Recuay, Rodrigo Hernández Príncipe registra que los llacuaces lo veneraban como Libiac, el rayo, Namoc, padre del rayo y Uchu Libiac, hijo del rayo. ${ }^{12}$ De acuerdo con la Relación de los agustinos

10 Mario Polia Meconi, La cosmovisión religiosa andina en los documentos inéditos del Archivo Romano de la Compañía de Jesús, 1581-1752, Lima, Pontificia Universidad Católica del Perú, 1999, p. 175. Diego González Olguín, Vocabvlario de la Lengva General de todo el Perv llamada Lengua Qquichua, o del Inca, digitalizado por Runasimipi Qespisqa, 2007. En http://www.runasimipi.org y www.illa-a.org/cd/ diccionarios/VocabvlarioQqichuaDeHolguin.pdf. Según el Diccionario quechua-español-quechua. Simi taqe, Perú, Millenium Editora Global, 2009, que se refiere al quechua actual, Illapa significa "Rayo, chispa eléctrica que fulgura en los descargues atmosféricos. Relámpago o fulgor deslumbrador que produce el rayo".

11 Polia Meconi, op. cit., p. 91.

12 Lamana, op. cit., p. 344. Felipe Guamán Poma de Ayala, El primer nueva corónica y buen gobierno, 3 vols., ed. crítica de John V. Murra y Rolena Adorno, trad. y análisis del quechua de Jorge L. Urioste, México, Siglo XxI, 1980, vol. I, p. 56. Felipe Guamán Poma de Ayala escribió su obra entre 1612 y 1616. Se presentó a sí mismo y a su padre como caciques principales y proclamaba que su madre era hija de Topa Inca Yupanqui. Estuvo en estrecha relación con el régimen colonial español. Fue escribano, litigante e intérprete. Su condición bicultural le permitió transitar entre el mundo español y el indígena. Tuvo contacto con autoridades virreinales y clérigos que escribieron importantes obras sobre la población andina, como Cristóbal de Albornoz y Martín de Murúa con quien tuvo fuertes conflictos. Conoció diversas crónicas españolas sobre los Andes. Su obra presenta valoraciones contradictorias, por ejemplo, exalta las mejores condiciones que existían en el régimen incaico, y se precia descender de la dinastía gobernante. Sin embargo, califica a ésta de ilegítima e idólatra, debido a que sigue el esquema toledano que pretendía difundir esa versión para justificar la 
de Huamachuco, los pobladores de esa región adoraban a Catequil en un cerro localizado en la actual jurisdicción de San José de Porcón, donde había tres peñas llamadas Apocatequil, Mamacatequil y Piguerao. Este sitio fue ubicado por John Topic en la montaña Icchal, en donde encontró un santuario anterior al dominio inca, que fechó hacia fines del Periodo Intermedio Temprano y durante el Horizonte Medio. También identificó al templo más tardío de ese lugar con el descrito en algunas fuentes, como la de Antonio de la Calancha, que narran que el recinto fue destruido, junto con la imagen pétrea, por orden de Atahualpa, ya que el oráculo vaticinó el triunfo de Huáscar en la guerra. Igualmente, Topic destaca los diversos aspectos de Catequil como dios del trueno y del relámpago, héroe cultural, ancestro fundador de la población y oráculo. Indica, además, que el ídolo, la montaña y sus acantilados constituían la esencia de la guaca. ${ }^{13}$

dominación española. Aunque minimiza lo traumático de la conquista, critica algunas medidas impuestas por el sistema colonial, sus excesos, injusticias y la pérdida de derechos de los indígenas. A pesar de la influencia española presente en su obra, como la afirmación de que el hombre andino desciende de Noé para ajustarse a los cánones de la época, su "corónica" proporciona datos de gran riqueza sobre la sociedad, la política, la economía, la administración pública y la religión andina. "Visita de Rodrigo Hernández Príncipe a Recuay (1622)”, en Duviols, Procesos..., p. 756.

13 John Topic, Andean Archaeology. Variation and Sociopolitical Organization, William Isabell and Helaine Silverman [eds.], Nueva York, Kluwer Academic/Plenum Publishers, 2002. En https://books.google.com.mx/books?isbn=1461506395-. Véase el capítulo 11. Pedro Sarmiento de Gamboa, Historia de los incas, $2^{\mathrm{a}}$ ed., Buenos Aires, Emecé, 1943, p. 157. Pedro Sarmiento de Gamboa (1532-1592). En 1555 llegó a la Nueva España y en 1557 a Perú. Fue capitán de navío y cosmógrafo. En la época del virrey Francisco de Toledo, y con la anuencia de éste, participó en la visita general al Reino del Perú. En ella obtuvo importante información, sobre todo en Cusco, que aprovechó para escribir su Historia de los Incas o Segunda parte de la historia general llamada Indica (1572). Su manuscrito fue encontrado a fines del siglo xix en la Universidad de Gottingen y fue editado por primera vez por Richard Pietschmann en 1906 en Berlín. Relación de los agustinos de Huamachuco, edición, estudio preliminar y notas de Lucila Castro de Trelles, Lima, Pontificia Universidad Católica del Perú, 1992, p. 19. Documento que contiene información relevante sobre la religión de los pobladores de la zona de Huamachuco. La relación fue escrita en España hacia 1560, posiblemente por uno de los doce agustinos que llegaron a Perú en 1551. De acuerdo con Lucila Castro de Trelles, su autor pudo haber sido fray Juan de San Pedro. 
Los pueblos que tenían al rayo como su dios patrono, creían que éste había sido el creador del género humano y el proveedor de los alimentos. Así, según el documento de Huarochirí, Pariacaca, deidad que controlaba las lluvias, las tormentas y el granizo, creó a los hombres, mientras que su contraparte femenina, Chaupiñamca, a las mujeres. ${ }^{14}$ Los habitantes de Huamachuco decían que Catequil extrajo a la humanidad del cerro Guacat al cavar con azadas de oro y plata. ${ }^{15}$ Esta acción mítica equipara al ser humano con las plantas, ya que ambos surgieron del interior de la tierra, donde fueron gestados por la divinidad terrestre. Sin embargo, la acción de sacarlos a la superficie se debió a Catequil, dios del rayo, con características fecundantes, que era considerado como padre de la humanidad por los pueblos que habitaban en esa región. Igualmente, para los llacuaces de la Provincia de Huaylas, su ancestro Libiac Cancharco, ${ }^{16}$ numen del rayo, había dado origen al género humano y a las plantas comestibles, además de que era quien otorgaba la vida, la lluvia y producía los alimentos, razón por la cual lo adoraban. ${ }^{17}$ En relación con esto, Bernardo de Noboa refiere que los llacuaces de San Francisco de Otuco rendían culto a Libiac tres veces al año para propiciar la fertilidad de la tierra. La primera celebración la hacían por Navidad, para que lloviera, la segunda en febrero, antes de

14 Francisco de Ávila, Dioses y bombres de Huarochirí, trad. de José María Arguedas, estudio introductorio de Luis Millones y Hiroyasu Tomoeda, estudio biobibliográfico de Pierre Duviols, Lima, Universidad Antonio Ruiz de Montoya, 2007, p. 77. Documento quechua de gran riqueza que contiene diversos mitos y costumbres de los antiguos pobladores de Huarochirí. Las narraciones, que seguramente provienen de diferentes informantes de la región, fueron recopiladas por orden de Francisco de Ávila, párroco de Huarochirí, en su intento por acabar con la antigua religión. Las historias sagradas que presenta el documento fueron trasladadas de la oralidad a la escritura entre el ocaso del siglo XVI y los albores del XVII en su idioma original. Ávila plasmó en castellano únicamente siete capítulos, los cuales en muchos casos no se ajustan a una traducción literal, además de que agrega comentarios y juicios propios.

15 Relación de los agustinos..., p. 17.

16 De acuerdo con Polia, op. cit., p. 91, cancharco proviene del vocablo k'ancharichiy que significa "hacer brillar".

17 Luis de Teruel, "Documento 30", en Polia, op. cit., p. 369. 
labrar sus sementeras, para que dieran buenas cosechas y, por último, en la fiesta de Corpus Christi, cuando comenzaba a darse el maíz. ${ }^{18}$

Como se puede apreciar, la realización de estas fiestas muestra la estrecha relación de la deidad con la producción de alimentos y la necesidad de venerarla para pedirle que les proveyera la manutención. Hay que destacar que las comunidades llacuaces, que adoraban a aquel dios, se dedicaban fundamentalmente al pastoreo de auquénidos, los cuales eran de gran relevancia en la economía andina, pues se utilizaban como animales de carga y de ellos se aprovechaba su carne como alimento, su lana para la confección de textiles y sus tendones para la elaboración de hondas. Además, dichos cuadrúpedos eran parte importante de la economía religiosa, pues había gran cantidad de hatos que pertenecían a las diferentes guacas para el sostenimiento de sus sacerdotes. Asimismo, eran aprovechados para el culto, ya que muchos de esos animales eran destinados al sacrificio como ofrenda y para realizar los vaticinios oraculares. Por lo tanto, era indispensable propiciar su fertilidad para que se reprodujeran.

El numen del rayo también presentó una faceta guerrera, pues algunos documentos refieren sus enfrentamientos con otras deidades, de los cuales el primero salió vencedor, lo que denotaba su supremacía y poder. Igualmente, la victoria de dicho dios aseguró la posibilidad de la existencia del ser humano sobre la tierra y el aumento de la población. Así, la tradición de Huarochirí relata la confrontación del agua y del fuego, personificados en Pariacaca y Huallalo Carhuincho, respectivamente. La contienda se desató porque este último sólo permitía a la gente tener dos hijos, uno de los cuales era devorado por él. Huallalo Carhuincho, que se manifestaba como fuego, lo cual podría significar la sequía y la imposibilidad de la agricultura, fue vencido por Pariacaca mediante tormentas, y esa lucha dio por resultado la formación de la laguna Mullococha, ubicada en la región de Lima. ${ }^{19}$ En otra parte de la región andina, la Relación de los agustinos de Huamachuco refiere que Catequil mató a los guachemines con las hondas que le había dejado su padre Guamansuri, y con ello el ser

18 "Visitas y procesos de Bernardo de Noboa", en Duviols, Procesos..., p. 227.

19 Ávila, op. cit., pp. 13, 49 y 51. 
humano pudo habitar en la tierra. Asimismo, la fuente dice que esa deidad era "el ydolo más temido y honrado que avia en todo el Perú; adorado y reverenciado desde Quito hasta Cuzco [...] es grande el acatamiento que tienen a Cataquil y el temor, porque dizen ques el que haze los rayos y truenos y relámpagos, los quales haze tirando con su honda $[. . .]^{\prime 2}{ }^{20}$

\section{EL RAYO COMO ANCESTRO}

De acuerdo con la antigua tradición andina, el primer ancestro de cada ayllu o grupo, luego de haber procreado, se transformaba en piedra, es decir, tenía la calidad de guaca y, por su carácter sagrado, era objeto de veneración. Igualmente, algunos documentos mencionan que los progenitores de diversos pueblos fueron ciertos mallkis, ${ }^{21}$ término con el que se designaba a los restos humanos de los antepasados que eran conservados por las comunidades. Dichos cuerpos eran resguardados en unos repositorios especiales, que podían ser cuevas o depósitos excavados ex profeso donde la gente los adoraba, ya que fungían como entidades protectoras y oráculos. Los mallkis tenían sus propios sacerdotes que se encargaban de su culto y que, además, eran sus intermediarios, pues transmitían sus designios y presagios a la población.

En diferentes pueblos de la cordillera de Perú, el dios del rayo no era únicamente una entidad mítica, intangible, o que sólo podía manifestarse a través del fenómeno meteorológico, sino que también era considerado como un ancestro encarnado en un ser humano. De esta manera, algunas comunidades llacuaces creín que sus mallkis más antiguos, de los que provenían, eran la personificación de esa deidad. Por ejemplo, los pobladores de la provincia de Huaylas tenían como antepasado a Libiac. Bernardo de Noboa registró que los habitantes de San Francisco de Otuco afirmaban que ese dios, al que llamaban Apu Libiac Cancharco, y sus des-

${ }^{20}$ Relación de los agustinos..., p. 18.

${ }^{21}$ De acuerdo con el diccionario de Diego Gonzáles Olguín significa "planta tierna para plantar" y "Qualquiera árbol frutal". 
cendientes habían sido sus progenitores. Por ello, veneraban sus cuerpos o mallkis que tenían resguardados en unas bóvedas debajo de la tierra. Luis de Teruel consignó en 1614 que los llacuaces de Huánuco también decían provenir del rayo o Libiac Cancharco, personaje que fue el primer cacique de la región. ${ }^{22}$

Resulta significativa la referencia registrada en los documentos de que los descendientes directos de los mallkis desempeñaran altos cargos en la sociedad o fungieran como sus sacerdotes e intermediarios. Esto denota la creencia de que existía una estirpe de origen sagrado que definía, al interior de la comunidad, una jerarquía socio-religiosa, en la que los puestos directivos eran ocupados por los individuos que guardaban un parentesco cercano con el dios. En relación con esto, Hernández Príncipe detalla la descendencia desde el fundador del linaje hasta algunos de los individuos que aún vivían en el siglo XVII, cuando el autor recopiló la información. Así, este visitador refiere que Caha Yánac, segundo hijo del dios del rayo llamado Carhua Huanca, era venerado por los caciques y por el gobernador de Ocros debido a que era su ancestro. Por lo tanto, la elite en el poder se consideraba descendiente de dicha deidad y en ello justificaba su posición privilegiada.

Ante la persecución de idolatrías y la destrucción de los antiguos objetos de culto, los indígenas reubicaron a sus guacas y mallkis, es decir, los desenterraron y depositaron en sitios alejados, donde creían que estarían fuera del alcance de los opresores. Por ello, muchos fueron escondidos en cerros y cuevas, sitios que eran considerados como numinosos. Sin embargo, a pesar de los esfuerzos de los indígenas por resguardar sus piedras sagradas y los restos mortales de sus ancestros, muchos de ellos no lograron escapar de la afanosa búsqueda de los visitadores. Así, fueron localizados mediante las confesiones forzadas de los indios obtenidas por medio de amenazas y, finalmente, los misioneros acabaron con buena parte de sus reliquias. Al respecto, Hernández Príncipe refiere que el ya mencionado Carhua Huanca y sus hijos, guacas de los habitantes de Ocros,

22 Polia, op. cit., p. 94 y Teruel, "Documento 30"..., p. 369. "Visitas y procesos de Bernardo de Noboa", en Duviols, Procesos..., p. 227. 
fueron trasladados de sus antiguos depósitos, ubicados en el pueblo, a la montaña Racian para evitar que fueran destruidos por Fernando Avendaño. Pero, tiempo después, Hernández Príncipe las descubrió "sentadas con majestad, con sus diademas, y chipanas [pulseras] de plata, aunque los vestuarios muy podridos, y a vista de los sacrificios de llamas y cuyes y sus aras donde encendían el incienso de ellas". ${ }^{23}$ Asimismo, Libiac Cancharco fue localizado por el tenaz Avendaño con su ropa, ornamentos y tres acompañantes en una cueva en la cumbre de un cerro, cerca de San Cristóbal de Rapaz. ${ }^{24}$

Esta campaña también se dio en México con igual violencia hacia las poblaciones indígenas, según se puede constatar en algunos expedientes del Archivo General de la Nación, como en los volúmenes publicados Procesos de indios idólatras y hechiceros y el Proceso inquisitorial del cacique de Texcoco, quien tuvo como fatal destino la muerte en la hoguera. Tanto las persecuciones en la Nueva España como las realizadas en Perú, no buscaban únicamente el interés religioso de convertir a los indígenas al catolicismo, sino que también tenían un trasfondo político, ya que las creencias y ritos paganos fungían como factor aglutinante de la población. De esta manera, dichas prácticas religiosas, que constituían una forma de resistencia, implicaban cierta peligrosidad, puesto que podían derivar en rebeliones contra el nuevo orden. Por ello los castigos aplicados por las autoridades españolas a los llamados idólatras. Esto se puede observar,

23 "Visita de Rodrigo Hernández Príncipe a Ocros (1621)", en Duviols, Procesos..., p. 734.

24 Polia, op. cit., pp. 89 y 90 y Teruel, "Documento 30"..., p. 370. Pablo Joseph de Arriaga, La extirpación de la idolatría en el Perú (1621), estudio preliminar y notas de Henrique Urbano, Cusco, Centro de Estudios Regionales Andinos "Bartolomé de las Casas", 1999, p. 18. Jesuita que llegó a Perú en 1585. Fue rector del Colegio de San Martín por 24 años y del Colegio de Arequipa durante 4. Se dedicó arduamente a la catequización de los indígenas y a acabar con la antigua religión en la sierra limeña. Durante su labor misionera recopiló importante información sobre las costumbres y las creencias indígenas que aún prevalecían en el siglo XVII, y que plasmó en su manuscrito La extirpación de la idolatría en el Perú (1621). Esta obra, que a su vez constituyó un manual para la extirpación, fue tempranamente editada en 1621 y gozó de una amplia difusión. 
por ejemplo, en el movimiento del taki onqoy en Perú y en la verdadera acusación que subyace en el juicio contra el cacique texcocano Don Carlos Ometochtzin, es decir, conspirar contra los invasores españoles. En ambos casos se instigó a los indígenas para que regresaran a su antigua religión, recurrieran a la desobediencia e incluso a la sublevación en contra de la dominación de los conquistadores, lo cual desembocó en represiones. ${ }^{25}$

\section{EL ORIGEN MÍTICO DEL DIOS DEL RAYO}

El celo de los visitadores por destruir las creencias y prácticas ancestrales que tanto abominaban, y que aún estaban vigentes entre los indígenas en los siglos XVI y XVII, los llevó a consignarlas en diversos documentos que han llegado hasta nosotros. Gracias a ello se han conservado algunos de los mitos que los antiguos pobladores de la sierra central y norcentral de Perú tenían sobre el origen del dios del rayo. Según las narraciones, la divinidad bajó del cielo como una centella, como una piedra, como un niño o como un hombre. Por ejemplo, Bernardo de Noboa registró que Libiac Rupac era la piedra de un rayo que se había desplomado, y a la que rendían culto los llacuaces de Santo Domingo de Pariac, de Pimachi y de Otuco. ${ }^{26}$ Bendiel de Salazar consignó en 1615, en la región de Huánuco, que los residentes del pueblo de Cauri veneraban en sus bailes a Yanaraman Libiac Cancharco, también llamado Libia Binac Vilca. Este último, nos dice el vi-

25 Sobre el taki onqoy véase Luis Millones, Taki onqoy: de la enfermedad del canto a la epidemia, estudio preliminar de Luis Millones, Santiago de Chile, Centro de Investigaciones Diego Barros Arana, 2007. Para los casos mexicanos véase Procesos de indios idólatras y bechiceros, México, Publicaciones del Archivo General y Público de la Nación, vol. I, 1912 y Proceso inquisitorial del cacique de Texcoco, México, Publicaciones del Archivo General y Público de la Nación, vol. III, 1910. Silvia Limón Olvera, "Ataque a indios idólatras por la inquisición: su sentido político", en Nuestra América, 20, México, CCyDEL-UNAM, 1991, pp. 11-31, y de la misma autora "El taki onqoy y los idólatras del centro de México. Resistencia y represión indígena en el siglo XVI", en Perspectivas Latinoamericanas, edición especial "El Taqui Onqoy", Nagoya, Japón, Centro de Estudios Latinoamericanos, Universidad Nanzan, 2015, pp. 41-55.

26 "Visitas y procesos de Bernardo de Noboa", en Duviols, Procesos..., pp. 264, 267 y 268. 
sitador, era un cerro ubicado a media legua de esa población, el cual se formó debido a que en ese sitio cayó un hombre del cielo, hecho que dio lugar a la formación de una protuberancia en el llano. Asimismo, menciona que Yanaraman Libiac Cancharco tuvo tres hijos, de quienes procedieron todos los habitantes de ese pueblo. Refirió también que, según la tradición de esa zona, dicha deidad provino del cielo como un recién nacido que fue encontrado por Atunchuca mientras cazaba vicuñas y venados en el cerro Raco. Este personaje se hizo cargo del niño, el cual creció rápidamente en cinco días y le dio la tarea de cuidar sus llamas. Sin embargo, Yanaraman Libiac Cancharco se convirtió en puma y se comió a varios auquénidos. Resulta significativo el lugar donde cayó el rayo encarnado en un bebé, ya que el cerro Raco fue identificado por Avendaño como la pakarina o lugar de origen de los llacuaces, sitio que también es mencionado con el nombre de Yaro, otro de los apelativos de la divinidad. ${ }^{27}$

En 1614 Fabián de Ayala recopiló en la Provincia de Chinchaycocha una narración según la cual en un gran peñasco llamado Ayracaca ("peñasco loco"), ubicado en los términos de Tarma, descendieron del cielo los hermanos Tumayricapa y Tumayhanampa. El primero se fue a la montaña Mamallqui Jirca ("planta, principio u origen de los cerros"), cerca de la laguna de Chinchaycocha o Lago Junín, donde reunió a todas las guacas. De allí se dirigió hacia las actuales provincias de Junín y Pasco, y se transformó en un bebé que fue recogido y criado por una mujer del pueblo de Guaychau. Al igual que en el otro caso mencionado, el niño, que era Tumayricapa, creció en cinco días. Ya como adulto recibió por sobrinos a los indios chupachos del valle de Huánuco mediante la ceremonia de trasquilarles los cabellos. Sin embargo, como los yanamates de Pasco no quisieron reconocerlo ni obedecerlo, Tumayricapa y Tumayhanampa les robaron un auquénido. Al buscarlo, encontraron a los hermanos al pie del cerro Caytal, uno de ellos en forma de puma que, al enojarse, arrojó granizo por la nariz, lo cual muestra la relación del felino con el fenómeno meteorológico que produce lluvias, tormentas y granizo. Finalmente, dicho grupo aceptó a Tumayricapa como padre, lo cual fue corroborado 
por las señales de las entrañas de una llama sacrificada. ${ }^{28}$ Cabe mencionar que el establecimiento del parentesco entre los grupos mencionados y ese personaje divino, ya sea como sobrinos o como hijos, significaba que éste se erigía como su dios patrono, con el compromiso que ello implicaba: rendirle culto. También llama la atención que, Tumayricapa, divinidad del rayo de los llacuaces, aparezca en el mito con un hermano y ambos, aunque la fuente no lo especifique, podrían haber sido gemelos, ya que éstos eran identificados con la deidad de las tormentas.

Los relatos anteriores muestran algunos elementos característicos de las antiguas creencias andinas. Entre ellos destaca la asociación de los personajes divinos mencionados con algunas montañas, las cuales eran consideradas como sagradas, ya que podían ser la representación de deidades, habitación de entidades míticas y expresión del eje cósmico, donde se podían manifestar seres y sucesos numinosos. También, sobresale el nexo que el dios del rayo guardaba con las llamas, animales a los que robaba y devoraba, pues constituían su principal alimento y ofrenda, debido a que era divinidad tutelar de los pueblos pastores. Así, los llacuaces rendían culto al dios del rayo porque tenía el poder de propiciar la reproducción de esos cuadrúpedos. Igualmente, tenían en sus santuarios piedras besares extraídas de los auquénidos, a las que llamaban illa, pues creían que aumentaban sus hatos. ${ }^{29}$

Cabe destacar que el aspecto distintivo de esta deidad era su manifestación como felino, lo cual remite al mito de Qówa, ser félido que andaba por las nubes, y que posiblemente a él se refieran las antiguas representaciones de Chavín de Huántar. ${ }^{30}$ Como dice Polia, "La deidad andina del Rayo (Llipiaq; Choq'e Illa; Illap'a) está tradicionalmente relacionada con la teofanía felínica cuya representación mítica es Qówa, o el 'Felino Vola-

28 Fabián de Ayala, "Una carta del P. Fabián de Ayala conforme al original del Archivo Romano de la Compañía de Jesús", notas y comentarios de Mario Polia, en Antbropologica, núm. 17, Lima, Pontificia Universidad Católica del Perú, 1999, pp. 389-395.

29 "Visita de Rodrigo Hernández Príncipe a Recuay (1622)", en Duviols, Procesos..., p. 760.

30 Federico Kauffmann-Doig, Introducción al Perú antiguo. Una nueva perspectiva, Lima, Kompaktos, 1990, p. 203. 
dor'." 31 En relación con esto, resulta interesante que en la actualidad la palabra "qówa" se refiera a "un animal parecido al gato montés", y que al mismo tiempo signifique "nubarrón que presagia granizada, nube grande y negra". ${ }^{32}$ La asociación de las tormentas con el felino ha pervivido al menos hasta mediados del siglo XX, ya que está registrada en el mito "La laguna de Schururo", recopilado en la sierra de Cajamarca. De acuerdo con esa narración, la madre o "espíritu" de la laguna era un puma que vivía en ese espejo de agua. El animal fue apresado por un brujo transformado en cóndor que lo elevó por los aires, pero la laguna lo siguió y formó una gran tempestad que liberó al cuadrúpedo. ${ }^{33}$

Cabe mencionar que después de la conquista, el dios del rayo fue identificado con el apóstol Santiago pues, como menciona Pablo Joseph de Arriaga,

[...] porque se habrá extendido por acá [en Perú] la frase o conseja de los muchachos de España, que cuando truena dicen que corre el caballo de Santiago, o porque veían que en las guerras que tenían los españoles, cuando querían disparar los arcabuces, que los indios llaman Illapa, o Rayo apellidaban primero 'Santiago, Santiago'. ${ }^{34}$

De esta manera, el dios del rayo como felino volador y Santiago compartieron la característica de andar por las nubes, las cuales son portadoras de lluvia.

Es pertinente señalar también que a las excreciones de los dioses se les atribuía la capacidad de creación, puesto que daban lugar a elementos y seres del mundo. Así, los orines de Qówa se transformaban en la lluvia que fecundaba la tierra y permitía la generación y crecimiento de las plantas. ${ }^{35} \mathrm{Al}$ respecto, Juan Pérez Bocanegra consignó en 1631 una fórmula

31 Polia, op. cit., p. 91.

32 Diccionario quechua-español-quechua Simi taque, Perú, Millenium Editora Global, 2009.

33 José María Arguedas y Francisco Izquierdo Ríos, Mitos, leyendas y cuentos peruanos, Madrid, Siruela, 2009, pp. 78 y 79.

34 Arriaga, op. cit., p. 64.

35 Kauffmann-Doig, op. cit., p. 203. 
ritual para solicitar lluvia que dice: "O madre fuente, laguna, ó manantial, dame agua sin cessar, orina sin parar." 36

Otro de los líquidos divinos relacionados con la fertilidad fueron las lágrimas de los dioses, puesto que, asimismo, daban lugar a la lluvia. Esto se puede apreciar en la imagen plasmada en la Puerta del Sol en Tiahuanaco, en donde se muestra un ser de contorno humano, parado encima de una estructura piramidal que podría corresponder a una montaña sagrada. El personaje ostenta ojos circulares, de los que escurren lagrimones en forma de puma. Por lo tanto, la figura en conjunto simboliza la fecundación de la tierra por parte del dios a través de sus lágrimas que representan el agua celeste. Esta deidad se puede equiparar con las imágenes mexicas de Tláloc, modeladas en los braseros de barro encontrados en el Templo Mayor de la ciudad de México, pues en ellos se observa al dios pluvial con lágrimas en los ojos. Este concepto tuvo su expresión ritual en las ceremonias de petición de lluvia que realizaban tanto los incas como los mexicas antes de la llegada de los españoles. Así, los pobladores de Cusco solían efectuar peregrinaciones por los cerros con llantos y gemidos para atraer el líquido celeste. Igualmente, acostumbraban amarrar una llama negra a la que dejaban en ayuno para que llorara, con el fin de que Illapa se apiadara e hiciera llover. En otras latitudes del continente americano, los mexicas sacrificaban infantes a Tláloc en la época de sequía y, si éstos lloraban durante la ceremonia, significaba que las lluvias no tardarían en llegar. ${ }^{37}$ Por tanto, las lágrimas de las deidades pluviales y las derramadas por los participantes en sus ritos, atraían el preciado líquido celeste que fertilizaría la tierra.

Las excrecencias divinas podían dar lugar, también, a grupos humanos. Según el mito recopilado por Fernando de Avendaño, algunos ayllus de llacuaces, que se consideraban hijos del rayo, decían provenir de la orina de ese dios, la cual fue depositada en un agujero junto al cerro Ra-

36 Citado en Polia, op. cit., p. 505.

37 Guamán Poma de Ayala, op. cit., vol. I, pp. 165, 210 y 229. Bernardino de Sahagún, Historia general de las cosas de la Nueva España, 3 vols., estudio introductorio, paleografía, glosario y notas de Alfredo López Austin y Josefina García Quintana, México, Conaculta, 2000, vol. I, pp. 177 y 178. 
co. ${ }^{38}$ Asimismo, Fabián de Ayala consignó que Raco, además de ser una montaña, era el dios de los alimentos al que se invocaba y rendía culto en la época de siembra, ${ }^{39}$ por lo que estaba asociado con la fecundidad.

\section{LOS ELEGIDOS}

Diversas fuentes andinas mencionan la estrecha relación que guardaban algunos individuos con el dios del rayo. A este respecto establecen que, tanto entre los llacuaces como entre los llactas, los mellizos, llamados chuchus o curis, y los que nacían de pies, conocidos como chacpas, eran considerados sus hijos, al igual que los nonatos, producto de los abortos. Si los gemelos y los que nacían de parto podálico sobrevivían, eran dedicados a dicha divinidad y estaban destinados a ser sus ministros. Se evitaba que éstos fueran bautizados dentro del catolicismo para que no perdieran las capacidades especiales conferidas por el dios y, al crecer, pudieran dirigir sus ceremonias. También se refiere que algunos de ellos eran sacrificados en su honor. ${ }^{40}$ Cuando estos infantes morían eran depositados, al igual que los nonatos, en unas ollas debajo de las casas, o los colocaban junto a los santuarios de la deidad para reverenciarlos, pues adquirían la connotación de oráculos. Como se creía que estos individuos habían sido procreados por la deidad, atribuían su defunción a que su padre, el rayo, se los había llevado consigo. Por eso, como registra un documento de la provincia de Huaylas, una mujer portaba siempre consigo una concha spondylus, a la que denominaban mullu, para evitar que el rayo la matara porque era gemela. Cabe mencionar que este material era una ofrenda importante dedicada al dios que proveía la lluvia, y que en este caso servía de protec-

38 Polia, op. cit., p. 91.

39 Ayala, op. cit., p. 397.

40 Guamán Poma de Ayala, op. cit., vol. I, p. 249. Arriaga, op. cit., pp. 39, 63, 128 y 130. Polia, op. cit., p. 181. Diego Samaniego, "Documento 28", en ibid., p. 334 y Anónimo, "Documento 32", en ibid., p. 410. "Relación de Fernando de Avendaño", en Duviols, Procesos..., p. 718 . 
ción. ${ }^{41}$ Sobre los mellizos, los jesuitas que visitaron en 1618 las provincias de Ocros y Lampas para extirpar las idolatrías, consignaron lo siguiente:

Quando vna mujer o vna oveja o qualquiera otro animal pare de un bientre dos, que llaman chuchu, el vno dizen que es el Rayo; y assi los veneran a ambos por no saber de cierto qual es y si muere alguno de ellos le guardan en vna olla, grande en el lugar donde guardan sus mallquis y alli le ofressen chicha, cuies, y lo demás que se a dicho. ${ }^{42}$

Es pertinente señalar que los mellizos recibían también el apelativo de Curi, otro de los nombres del dios, para denotar su afinidad con él. En la época colonial, los llamaban Santiago pues, como ya se refirió, dicho apóstol fue identificado con el rayo. Sin embargo, esta práctica fue prohibida por los misioneros españoles debido a que fue calificada de idolátrica. ${ }^{43}$

Igualmente, eran considerados como hijos del rayo las criaturas que nacían en el campo durante una tormenta y, por lo tanto, ejercerían como sus sacerdotes, pues se creía que las ofrendas que ellos daban eran mejor recibidas por el dios. Sobre esto, Polo Ondegardo señala que: "Cuando una mujer pare en el campo en día que truena, dicen que la criatura que nace es hijo del Trueno; y que se ha de dedicar para su servicio. Y así hay mucho número de hechiceros de estos, que llaman hijos del Trueno." ${ }^{\prime 4}$ Lo mismo acontecía con los individuos que sobrevivían a la caída de una centella, quienes, además, adquirían la capacidad de curar. Tanto los descendientes de éstos como los sucesores de los que habían muerto a causa del rayo, recibían el nombre de Curi, por lo que la identificación con la deidad se extendía a las generaciones posteriores.$^{45}$ Con respecto a los tocados por el rayo, existen algunas semejanzas con el centro de México pues,

41 “Visita de Rodrigo Hernández Príncipe a Recuay (1622)", en ibid., p. 757. Diego Álvarez de Paz, "Documento 33", en Polia, op. cit., p. 415. Arriaga, op. cit., p. 64.

42 "Misión a las Provincias de Ocros y Lampas del Corregimiento de Cajatambo", en Duviols, Procesos..., p. 727.

43 Arriaga, op. cit., p. 173.

${ }^{44}$ Lamana, op. cit., p. 344.

45 Samaniego, en Polia, op. cit., p. 334, Gonzalo de Lyra, "Documento 38", en ibid., p. 449 . 
desde el siglo Xvi hasta la actualidad, se ha registrado que algunos de los que han sobrevivido a la caída del rayo pueden sanar a los afectados por este fenómeno meteorológico, mientras que otros adquieren la capacidad de controlar la lluvia, el granizo y las tormentas.

Diversas comunidades andinas creían, asimismo, que las criaturas que habían sido concebidas durante una tempestad tenían como padre al rayo. Se pensaba que las mujeres preñadas de esta manera podían parir piedras, las cuales eran muy apreciadas porque los vaticinios que se hicieran con ellas siempre resultaban acertados. En relación con esto, un documento jesuita de la provincia de Huaylas relata que cuando una mujer parió una criatura muerta, salió al mismo tiempo de su vientre una luminosidad con un gran estruendo que era el hijo del dios. Las fuentes, igualmente, consignan que los infantes podían ser consagrados al rayo si se sacrificaban llamas a la deidad o si el niño era expuesto a una tormenta. ${ }^{46}$

Cuando una mujer daba a luz mellizos, ella, su marido y parientes debían cumplir con un ayuno de sal y ají, así como abstenerse de relaciones sexuales por diferentes periodos de tiempo, los cuales podían durar hasta un año. De acuerdo con Fabián de Ayala, esta observancia era hecha por la recién parida para no quedar embarazada nuevamente del rayo. Cabe señalar que estas restricciones constituían prácticas de purificación, las cuales también debían ser cumplidas, por ejemplo, por cualquier individuo que fuera a participar en algún rito. Además, la recién parida, el marido o ambos debían observar una conducta ritual que fue entendida por los visitadores como "penitencia". Ésta consistía en que los cónyuges debían encerrarse en un aposento y quedarse acostados por varios días, primero de un lado y luego del otro. ${ }^{47}$

De igual forma, el jesuita Joseph de Arriaga interpretó que el dar a luz gemelos era considerado como un pecado. Al respecto comenta que: "Tienen en su nacimiento muchas supersticiones [...] todas enderezadas

46 Lamana, op. cit., p. 355. Rodrigo de Cabredo, "Documento 13", en Polia, op. cit., p. 234, anónimo, en ibid., p. 410, Lyra, en ibid., p. 449.

47 Arriaga, op. cit. pp. 63 y 171. Teruel, "Documento 30"..., p. 367. Juan Sebastián de la Parra, "Documento 22"..., p. 279. Ayala, op. cit. p. 358. Guamán Poma de Ayala, op. cit., vol. I, p. 249 y vol. II, p. 728. Relación de los agustinos..., p. 29. 
a hacer penitencia, para que se les perdone el pecado, que entienden que fue el haber nacido dos juntos." ${ }^{48}$ Asimismo, menciona que el parir mellizos "lo tienen por cosa sacrílega y abominable, y aunque dicen que uno es hijo del Rayo, hacen grande penitencia, como si hubiesen hecho un gran pecado" ${ }^{49}$ Poco más adelante relata que, una vez terminado el ayuno, paseaban a los padres en un palio hecho de piel de venado. Resulta interesante que el jesuita se refiera a los progenitores de los gemelos como "penitentes", pues indica que los identificó con los que eran juzgados por la Inquisición, quienes eran expuestos al escarnio público al llevarlos por las calles y plazas. En contraposición a lo anterior, el Inca Garcilaso de la Vega consigna que la mujer que paría mellizos era sacada a la calle "con gran fiesta y regocijo", le ponían guirnaldas de flores, hacían grandes bailes y cantares por su mucha fecundidad, y que tanto a los gemelos como a la madre los llamaban guaca. En tanto que otro documento procedente de Lima afirma que cuando terminaba el periodo de abstinencia de la madre, todos iban a venerar a los gemelos para que no les sucediera ningún daño. ${ }^{50}$

El hecho de que algunos individuos, como los mellizos, fueran considerados hijos de la divinidad y que una mujer los hubiera procreado, indica que eran receptáculo de lo sagrado, por ello, eran calificados como guacas. En relación con esto, es pertinente señalar que el contacto con la sacralidad resulta peligroso para cualquier persona que no esté lo suficientemente preparada para ello. Así, las penitencias y el encierro obligados de la recién parida, y en ocasiones del marido, se debían al contacto que había tenido el dios del rayo con la mujer y sus hijos. De esta manera, el aislamiento y las abstinencias tenían como objetivo disminuir la carga sagrada que estos individuos contenían por haber estado en contacto con la deidad, y así amortiguar el daño que esto pudiera causar al resto de la población. Igualmente, los parientes debían observar restricciones en cuanto al consumo de sal y ají, así como abstenerse de relaciones conyugales para fortalecerse y poder acercarse sin riesgo a la mujer, a su esposo y al hijo del rayo. Debido a la

Arriaga, op. cit., p. 39.

49 Ibid., p. 63.

50 De la Vega, op. cit., p. 77. De la Parra, "Documento 22"..., p. 280. 
peligrosidad que implicaba el contacto con esos recién nacidos y su madre, la gente tenía miedo de visitarlos antes de que se terminara el periodo de purificación. Por lo tanto, no se trataba de un "pecado" como lo consigna Arriaga pues, además, hay datos que apuntan a que los "hijos del rayo", los auquénidos que nacían dos de un vientre, así como las mazorcas de maíz, el ají y las papas que se daban dobles, eran considerados como contenedores de la fuerza vital de esas especies y símbolo de fertilidad. Por ello, las veneraban para que tanto las llamas como los campos fueran fructíferos. ${ }^{51}$

\section{A MANERA DE CONCLUSIÓN}

Con base en lo expuesto, se puede apreciar que los documentos elaborados en los siglos XVI y XVII, y que provienen de regiones ajenas al núcleo cusqueño, presentan perspectivas diferentes a lo consignado por la tradición inca sobre la divinidad del rayo y su culto. Esto hace visible los contrastes regionales y la heterogeneidad que hubo en cuanto a las concepciones que sobrevivieron a la conquista española. También permite destacar que, a pesar de la ideología religiosa que fue impuesta por los incas a los pueblos sometidos, las poblaciones de llacuaces y llactas de la sierra central y norcentral de Perú, conservaron sus antiguas prácticas y creencias al menos hasta el siglo XVII, época del embate de la persecución de idolatrías. Sin embargo, esta virulenta campaña dejó importantes registros que permiten conocer las particularidades de sus tradiciones.

A través del estudio de la religión de esos pueblos se ha podido profundizar en la forma en que sus habitantes concibieron, explicaron y se relacionaron con su realidad, es decir, con su entorno social y natural, en donde tuvo un lugar preeminente el fenómeno de las tormentas, concebido como numinoso y cuyo control atribuyeron a su dios principal. Igualmente, se pudo observar que la ideología religiosa permeó a la sociedad, principalmente en su articulación con el ámbito sagrado. De esta manera, se

51 Guamán Poma de Ayala, op. cit., vol. I, p. 219. Arriaga, op. cit., p. 38. De la Vega, op. cit., p. 77. Relación de los agustinos..., p. 40. 
constata que el derecho a los altos cargos del gobierno y del sacerdocio en dichas comunidades estuvo definido por la descendencia directa del ancestro, el cual fue identificado con el dios del rayo, que era su patrono. También, la gente común estableció nexos especiales con la divinidad a través de determinadas personas que consideraban sus vástagos, como los mellizos, los nacidos de parto podálico o durante una tormenta, los tocados por el rayo y los que habían sido concebidos durante un temporal. Estos individuos elegidos por la deidad eran dedicados a ella y, por lo tanto, eran sus intermediarios, ya fuera como sus sacerdotes mientras vivían o como oráculos una vez que habían muerto. Así, dicha connotación los colocaba en una posición privilegiada dentro de la comunidad.

Es importante señalar que en la región convivieron dos etnias cuya procedencia y tradiciones eran diferentes: los pastores llacuaces descendientes del rayo, y los llactas, agricultores que decían ser hijos del sol. Sin embargo, la solución a sus diferencias se dio en el plano religioso al compartir el culto al rayo, dios patrono de los llacuaces, relacionado con la lluvia, la cual era necesaria para ambos, ya que al fecundar la tierra hacía crecer las plantas que alimentaban a los seres humanos y a los auquénidos, animales que tuvieron un lugar relevante en la economía andina. Por último, se ha podido apreciar que el sistema religioso proveyó la justificación de la preeminencia en el poder de determinados individuos, así como la explicación de los conflictos entre las dos etnias, cuyo origen se remitía al tiempo mítico, y presentó soluciones a través de la práctica ritual.

BiBLIOGRAFÍA

ARguedas, José María y Francisco IZQuierdo Ríos, Mitos, leyendas y cuentos peruanos, Madrid, Siruela, 2009.

ARRIAGA, PABlo JosePh de, La extirpación de la idolatría en el Perú (1621), estudio preliminar y notas de Henrique Urbano, Cuzco, Centro de Estudios Regionales Andinos "Bartolomé de las Casas", 1999.

ÁvILA, FRANCISCO DE, Dioses y hombres de Huarochirí, trad. de José María Arguedas, estudio introductorio de Luis Millones y Hiroyasu Tomoeda, 
estudio biobibliográfico de Pierre Duviols, Lima, Universidad Antonio Ruiz de Montoya, 2007.

AYALA, FABIÁN DE, "Una carta del P. Fabián de Ayala conforme al original del Archivo Romano de la Compañía de Jesús", notas y comentarios de Mario Polia, en Anthropologica, núm. 17, Lima, Pontificia Universidad Católica del Perú, 1999, pp. 377-406.

Diccionario quechua-español-quechua Simi taque, Perú, Millenium Editora Global, 2009.

Duviols, PierRe, "Huari y Llacuaz. Agricultores y pastores. Un dualismo prehispánico de oposición y complementariedad", en Revista del Museo Nacional, t. XXXIX, Lima, 1973, pp. 153-191.

, Procesos y visitas de idolatrías. Cajatambo siglo XVII, revisión paleográfica de Laura Gutiérrez Arbulú y Luis Andrade Ciudad, selec. de textos y estudios históricos de Pierre Duviols, trad. de textos quechuas de César Itier, Lima, Instituto Francés de Estudios Andinos/ Pontificia Universidad Católica del Perú, 2003.

González Holguín, Diego, Vocabulario de la Lengva General de todo el Perv Ilamada Lengua Qquichua, o del Inca, digitalizado por Runasimipi Qespisqa, 2007. En http://www.runasimipi.org y www.illa-a.org/ cd/diccionarios/VocabvlarioQqichua DeHolguin.pdf.

GuAMám POMA DE AYALA, FeliPE, El primer nueva corónica y buen gobierno, 3 vols., ed. crítica de John V. Murra y Rolena Adorno, trad. y análisis del quechua de Jorge L. Urioste, México, Siglo XXI, 1980.

Kauffmann-Doig, Federico, Introducción al Perú antiguo. Una nueva perspectiva, Lima, Kompaktos, 1990.

Lamana Ferrario, Gonzalo [ed.], Pensamiento colonial crítico. Textos y actos de Polo Ondegardo, estudio biográfico de Teodoro Hampe Martínez, Cusco, Centro de Estudios Regionales Andinos "Bartolomé de las Casas"/Instituto Francés de Estudios Andinos, 2012.

LIMÓN OLVERA, SILVIA, "Ataque a indios idólatras por la inquisición: su sentido político", en Nuestra América, 20, México, CCyDEL-UnAm, 1991, pp. $11-31$. 
,"El taki onqoy y los idólatras del centro de México. Resistencia y represión indígena en el siglo xv", en Perspectivas Latinoamericanas, edición especial "El Taqui Onqoy", Nagoya, Japón, Centro de Estudios Latinoamericanos-Universidad Nanzan, 2015, pp. 41-55.

Millones, LuIs, Taki onqoy: de la enfermedad del canto a la epidemia, estudio preliminar de Luis Millones, Santiago de Chile, Centro de Investigaciones Diego Barros Arana, 2007.

POLIA MECONI, MARIO, La cosmovisión religiosa andina en los documentos inéditos del Archivo Romano de la Compañía de Jesús, 1581-1752, Lima, Pontificia Universidad Católica del Perú, 1999.

Proceso inquisitorial del cacique de Texcoco, México, Publicaciones del Archivo General y Público de la Nación, vol. III, 1910.

Procesos de indios idólatras y hechiceros, México, Publicaciones del Archivo General y Público de la Nación, vol. I, 1912.

Relación de los agustinos de Huamachuco, edición, estudio preliminar y notas de Lucila Castro de Trelles, Lima, Pontificia Universidad Católica del Perú, 1992.

ROSTWOROWSKI, MARÍ, Estructuras andinas del poder. Ideología religiosa y política, Lima, Instituto de Estudios Peruanos, 2007.

SAHAGÚN, BERNARDINO DE, Historia general de las cosas de la Nueva Espa$\tilde{n} a, 3$ vols., estudio introductorio, paleografía, glosario y notas de Alfredo López Austin y Josefina García Quintana, México, Conaculta, 2000. Sarmiento de GamboA, Pedro, Historia de los incas, $2^{\text {a }}$ ed., Buenos Aires, Emecé, 1943.

TopIC, JoHn, Andean Archaeology. Variation and Sociopolitical Organization, William Isabell and Helaine Silverman [eds.], New York, Kluwer Academic/Plenum Publishers, 2002. En https://books.google.com.mx/ books?isbn $=1461506395$.

VEGA, GARCILASO DE LA, Comentarios reales de los incas, ed., índice analítico y glosario de Carlos Araníbar, 2 vols., México, FCE, 1995. 